Articulación de intereses, lobby, supervivencia organizacional, marketing político, Organización de los Moȳāhedīn-e Jalq-e Iran

\title{
LA ARTICULACIÓN DE INTERESES DE LOS MOȲĀHEDĪN-E JALQ-E IRAN: DE LA REVOLUCIÓN ISLÁMICA AL MOVIMIENTO VERDE ${ }^{1}$
}

\author{
MOISÉS GARDUÑO \\ Universidad Nacional Autónoma de México
}

Los Moȳāhedīn-e Jalq-e Iran son una organización que se creó a mediados de los años sesenta con el objetivo de derrocar a la dinastía Pahlevĩ en Irán y crear, sobre la base de su análisis social y religioso, una alternativa política para su país. Su participación en las protestas y los enfrentamientos armados contra las fuerzas policiales, militares y de inteligencia de la monarquía iraní coadyuvó estratégicamente al triunfo de lo que hoy se conoce como la Revolución islámica de Irán, proceso donde dicha organización desempeñó un papel relevante no sólo por su capacidad de movilización entre las masas de la clase media iraní, sino también por la eficacia de sus ataques selectivos contra el gobierno y el ejército monárquicos.

Sin embargo, tras la revolución de 1979, el choque de intereses creados entre los moȳähedìn y la nueva élite comandada por el ayatola Jomeini originó un ambiente de tensión y desconfianza que desembocaría en una nueva confrontación armada entre ambos actores. Dicho conflicto llevó a este grupo a esta-

Este artículo fue recibido por la dirección de la revista el 15 de mayo de 2014 y aceptado para su publicación el 15 de octubre de 2014.

${ }^{1}$ Este artículo fue elaborado a partir de mi tesis doctoral: "La articulación de objetivos y el marketing político como estrategias de supervivencia en el cambio organizacional de los Moȳāhedīn-e Jalq-e Iran, 1964-2012”, defendida en octubre de 2012 en la Universidad Autónoma de Madrid. Agradezco el financiamiento del programa de cooperación entre la Fundación Carolina de España y la Secretaría de Relaciones Exteriores de México, así como del programa de financiamiento para el personal investigador en formación de la Universidad Autónoma de Madrid. Sāzmān-e Moȳāhedīn-e Jalq-e Iran se traduce al español como Organización de los Moȳāhedīn del Pueblo de Irán. En este artículo se hace referencia a la organización indistintamente como los Moȳāhedīn-e Jalq-e Iran, los Moȳāhedīn-e Jalq-e o simplemente los moȳāhedīn. 
blecer una alianza con el gobierno de Sadam Husein, quien les dotó de armas, dinero y entrenamiento militar suficientes para golpear a la naciente República Islámica de Irán en su propio territorio, asesinando a varios personajes clave de la política iraní de aquella época e iniciando un conflicto que persiste hasta el momento de escribir estas líneas.

La posición estratégica que los moȳähedin tuvieron en Iraq se desvaneció ante la invasión estadounidense a ese país en 2003, y dejó a la organización con el dilema de desaparecer o cerrar filas con influyentes políticos de los gobiernos invasores, decisión la última que fue adoptada por sus líderes Mariam y Masud Rayavi en aras de lograr su supervivencia política, con una retórica que buscaría una "República Islámica Democrática" en Irán.

Tras el inicio de una nueva etapa de mutua demonización entre Irán y Estados Unidos, en 2002, algunos cuadros políticos de las potencias occidentales y de Tel Aviv dejaron claro que los moȳähedin podrían ser de mucha utilidad ante cualquier escenario de confrontación bélica con Teherán. ${ }^{2}$ Este discurso es repetido por las élites más conservadoras de ambas partes, incluso tras el reciente acuerdo alcanzado entre el G5+1 y Teherán, en la denominada cuestión nuclear. ${ }^{3}$

Así, con sedes en París, Washington y Londres, lugares donde han cosechado un amplio respaldo entre las derechas, los moyähedin usan un discurso de defensa de la democracia, el Estado laico y el respeto a los derechos humanos como mecanismo de

${ }^{2}$ A. Jafarzadeh, The Iran Threat: President Abmadinejad and the Coming Nuclear Crisis, Nueva York, Palgrave, 2007, pp. 11-13.

${ }^{3}$ Como Grupo cinco más uno se conoce a los seis países que se reunieron en 2006 para encontrar una salida negociada con Irán respecto de su programa nuclear. Los países que forman este grupo son Estados Unidos, Rusia, China, así como el grupo conocido como "los tres de la Unión Europea”, formado por Inglaterra, Francia y Alemania. Cabe señalar que este último miembro es un socio comercial clave para Teherán en cuestiones de tecnología nuclear. El 19 de enero de 2014 entró en vigor un acuerdo temporal entre todas las partes, donde se prevé el desmantelamiento gradual de las sanciones impuestas a Irán a cambio de la suspensión del enriquecimiento de uranio a 20\%. El 24 de noviembre de 2014 se revisaría este acuerdo con miras a extender su aplicación. Esto devino en el acuerdo del 14 de julio de 2015 en el cual se firmó el Joint Comprehensive Plan of Action que dio luz verde al programa nuclear de Irán a cambio de un gradual desmantelamiento de sanciones por parte de Occidente. Véase Tasnim News Agency, "Iran, G5+1 to resume Expert-Level Talks in Vienna”, Tasnimnews.com, 21 de octubre de 2014. 
justificación política. Sin embargo, en este artículo se defiende la hipótesis que ve la supervivencia de este grupo como un producto de la articulación de intereses con diversos actores políticos a lo largo de su historia y no tanto por la efectividad que tenga dicho discurso entre la sociedad iraní.

Si bien se trata del actor de oposición mejor organizado fuera de Irán hoy en día, los moȳähedìn siguen vivos debido a la manera en la que han vendido sus servicios a los aliados que alguna vez fueron sus más acérrimos enemigos en la escena internacional, lo cual se denomina, en términos de Bob Clifford, marketing político, es decir, la comercialización de ideas políticas y la articulación de intereses que un grupo hace con otro para empoderarse y que, en el caso que se presenta, busca convertir una causa local (la suya) en una causa global, para tener una mayor validación social. ${ }^{4}$

\section{Ideología fundacional de los Moȳāhedīn-e Jalq-e Iran en tiempos de la Revolución islámica}

De acuerdo con su historia oficial, los moȳāhedin se definieron, en sus orígenes, como un grupo que "deseaba establecer una organización musulmana, revolucionaria, nacionalista y democrática para el cambio en Irán", cuyas características se inspiraron en las organizaciones político-militares de insurgencia que hicieron posibles las luchas de liberación nacional en África; de manera particular, en el movimiento de la descolonización argelina. ${ }^{5} \mathrm{La}$ ideología fundacional de los moȳähedin se basó en una interpretación propia del Corán y los dichos y hechos del Profeta, esto desde una metodología marxista, la cual, según ellos, "estaría encaminada a darle un sustento científico e intelectual a su activismo político al entenderla como el único medio capaz de sacar a los pueblos de la opresión del capitalismo". ${ }^{6}$

${ }^{4}$ B. Clifford, The Marketing of Rebellion: Insurgents, Media, and International Activism, Cambridge, Cambridge University Press, 2005, p. 6.

${ }^{5}$ Mojahedin-e Khalq-e Organization, "Mojahedin Structure", Foreign Affairs Committee of the National Council of Resistance of Iran Bolletin, s.n., 23 de marzo de 2009.

${ }^{6}$ Sāzmān-i Mujāhidīn-i Khalq Iran, Shinākht [yā] mituduluzhì [Conocimientos y metodología], Teherán, Sāzmān-i Mujāhidīn, 1972, p. 142. 
Aplicar dicha metodología al islam implicaba generar una opinión particular de los moȳähedinn sobre el profeta Muhammad, al decir que ciertamente "el Profeta había aparecido en la tierra no para imponer una nueva madhab-i tawhidì (religión monoteísta), sino para instaurar toda una comunidad sin clases ('ummat-t tawebidya) con características dinámicas, constantes y tendentes hacia el progreso, el igualitarismo y la eventual perfección". ' Así, al justificar el potencial de la institución del iȳt $i$ bād (interpretación) en la shic $\bar{i}^{-} a$, la organización defendió la capacidad de adaptación del Corán a las nuevas características del tiempo, tal como el acto de sacrificio del imam Husein en los episodios de Kerbalá, el cual no era más que "el vivo ejemplo de cómo, mediante una revuelta armada y una conciencia de clases, un buen musulmán, revolucionario, creyente y dispuesto a morir por defender su causa, pudo ser capaz de cambiar el curso y el significado de la historia al pelear a muerte contra los ostentadores del poder". ${ }^{8}$

Los moyāhedīn inyectaron nuevos significados a viejos términos del islam en general, y de la shíc $a$ en particular. En sus trabajos, por citar algunos ejemplos, el significado de 'umma cambió de "comunidad de creyentes" a "sociedad dinámica tendente a la perfección"; tawhìd, de "monoteísmo" a "igualitarismo"; yihād, de "esfuerzo" a "lucha de liberación"; shabid, de "mártir religioso" a "héroe revolucionario"; moyāhed, de "guerrero religioso" a "luchador por la libertad"; tafsìr , de "estudio académico de los textos sagrados" a "proceso de la revelación revolucionaria"; iytibād, de la "práctica del uso de la razón para deducir algunas leyes específicas del islam" a la "práctica de diseñar leyes revolucionarias para las mismas leyes"; mo "men, de "creyente pío" a "verdadero luchador por la justicia"; kâfer, de "incrédulo" de la religión a "apático e indiferente" a la revolución; imàm, de "líder religioso" a "líder revolucionario"; bot parast, de "pagano" o "adorador de ídolos" a "adorador de la propiedad privada", y

7 Sāzmān-i Mujāhidīn-i Khalq Iran, Rāh-i anbiyā, rāh-i basher [Guía de los profetas, una guía para la humanidad], Teherán, Sāzmān-i Mujāhidīn, 1979, p. 242. También en Manuel Ruiz Figueroa, La religión islámica: una introducción, México, El Colegio de México, 2002, p. 157.

${ }^{8}$ M. Abrishamchi, Falsafah-'i imām zamān [Filosofía del imām oculto], Teherán, Anjuman-i dānishjūyān-i musalmān-i Dānishkadah-i Pulī Tiknīk, 1980, p. 2. 
uno de los más notables, mostaża ffìn, de "manso" o "desprotegido" a "oprimido" o "privado de algo". Este último término sería uno de los más usados durante el marketing de la organización con Jomeini, en el advenimiento de la revolución de 1979. ${ }^{9}$

Los inicios del marketing político de los moȳābedin en los años sesenta y setenta descansaban en dicha terminología, la cual no tenía como objetivo, en principio, el descalificar a la rühaniȳat ${ }^{10}$ sino al capitalismo y al imperialismo comandado por Estados Unidos y sus aliados regionales, pues, según los moȳahedin, el imperialismo estadounidense tendría el objetivo de apoderarse de los recursos naturales de Irán y, mediante la alianza con el shah, fortalecer un sistema capitalista que llevaría a la miseria y a la desigualdad en el país. Su lema fue, por excelencia, "morg beh amrik $\vec{a}$ " (muerte a Estados Unidos) y la táctica consistió en elaborar una campaña de legitimación de la lucha armada como único medio para la liberación. ${ }^{11}$

Y aunque la ideología de los moȳāhedīn no era bienvenida entre muchos movimientos de la época con tendencias marxistas, comunistas, islamistas o nacionalistas, todos estos grupos tenían el firme objetivo de terminar con la monarquía Pahlevī. ${ }^{12}$ En este contexto de pluralidad ideológica con metas comunes, la organización optó por vender sus ideas a través del pensamiento de autores de la talla de Mahmud Tạleqani, MehdiBazarĝan, y Ali

\footnotetext{
${ }^{9}$ E. Abrahamian, Radical Islam: The Iranian Mojahedin, Londres, Tauris, 1989, p. 96.

10 Término con el que se conoce al cuerpo de autoridades religiosas que se creó en tiempos previos a la Revolución islámica de 1979 y que fue determinante para organizar la oposición a la monarquía Pahlevī. Gente como Muhammad Reza Mahdava Kani, Jomeini, Rafsanyani y Ali Jamenei pertenecen a esta cúpula de poder en Irán que está presente en el parlamento, la presidencia y la Asamblea de Expertos. Véase Farzin Sarabi, "The Post-Khomeini Era in Iran: The Elections of the Fourth Islamic Majlis", Middle East Journal, vol. 48, núm. 1, invierno, 1994, pp. 89-107.

${ }^{11}$ Abrishamchi, Falsafab-'i..., op. cit., p. 58.

${ }_{12}$ Otros grupos que lucharon contra la monarquía fueron: Sāzmān-e Cherīk-e Fedā’iyān-e Jalq-e Iran; Sāzmān-e Peykār dar Rāh-e- Âzād-e-Tabaqeh-e Kargār (Organización de Luchadores por el camino de la Libertad de la Clase Trabajadora), que de 1975 a 1979 fue conocida como los Moȳāhidīn Marxistas y después de la revolución adoptaron el nombre de Sāzmān-e Peykār dar Rāh-e- Âzād-e-Tabaqeh-e; el grupo de 'Abū Zahr; el grupo de la Verdadera Shī'a; el grupo de Allah 'A k̇bar, y el grupo de 'Al Fayār, entre otros más pequeños. Véase mayor detalle en H. Dabashi, Theology of Discontent: The Ideological Foundations of the Islamic Revolution in Iran, Nueva York, New York University Press, 1993, p. 15.
} 
Shariati, ${ }^{13}$ cuyos escritos y reformulaciones sobre el islam revolucionario fueron ampliamente reconocidos entre la gente joven y universitaria dentro y fuera de Irán, y con quienes la organización se identificó rápidamente al creer que ellos propagarían su ideología entre las masas mientras, de manera clandestina, fraguaban las primeras operaciones armadas contra el aparato de seguridad del régimen que incluía al ejército, la policía y la Savak. ${ }^{14}$

Entre 1969 y 1971, los moȳähedin crearon una base de operaciones clandestina en Teherán y formaron un Comité Central que albergaría a los miembros más influyentes de la organización, entre ellos, Masud Rayavi, actual líder ideológico (y en estado de ocultamiento). Bajo dicho empeño, el entrenamiento de los primeros cuadros se dio a través del contacto que los moȳa-

${ }_{13}$ Taleqani, por ejemplo, de 1969 a 1971 estuvo desafiando al gobierno con varias acciones, tales como pedir dinero para enviarlo al pueblo palestino debido a la ineficacia de los países árabes y no árabes para resolver el conflicto. Como represalia, la monarquía le prohibió dirigir la oración del viernes en Teherán durante mucho tiempo, incluido el mes del Ramadán, por lo que las personas, miles de ellas, se congregaban afuera de su casa para oír sus sermones. Véase, sobre su apoyo económico a los moȳähedìn en tiempos de la Revolución islámica, A. Vakily, "In Search of Revolutionary Islam: The Case of Taleqani and Mojahedin”, The Muslim World, vol. 88, núm. 1, enero de 1998, pp. 22-46. Por otro lado, también es verdad que, pese a esta alianza pragmática y las semejanzas antes expresadas, hubo diferencias significativas entre la organización y los intelectuales, principalmente con Shariati, quien también pensaba, influido por los nacionalistas africanos que había conocido en Francia, que los países del mal llamado "tercer mundo" encontrarían una "tercera vía" tanto al capitalismo como al socialismo para su desarrollo, mientras que los moȳāhedin no veían otra opción más que la marxista, al tiempo de criticar a los líderes de las llamadas naciones "no alineadas" al decir que lo único que ofrecían eran "falsas esperanzas". Véase con atención Sāzmān-i Mujāhidīn-i Khalq Iran, Prāgmātism, Teherán, Intishārāt-i Sāzmān, 1979, pp. 12-13; También Haq Shenās, 'Intishār ârshîf sāzm nn peȳkār dar rāh âzādī tabaqeh-ȳe kārồar torāb haq shenās [publicación de archivos de la organización peȳkār dar rāh âzādī de la clase trabajadora por Torāb Haq Shenās], París, Sāzmān Peȳkār, 2011, p. 10. También se puede consultar Abrahamian, Radical Islam, op. cit., p. 125, y A. Singleton, Saddam's Private Army: How Rajavi changed Iran's Mojahedin from Armed Revolutionaries to an Armed Cult, Londres, Interlink, 2003, p. 58.

${ }^{14}$ Savak (Sāzmān-e Itțilā'àt va 'Amnīyat-e Keshvar) es el acrónimo, en farsi, de Organización de Inteligencia y Seguridad Nacional, que trabajó para la monarquía Pahlevī entre 1957 y 1979. Creada con ayuda de la Agencia Central de Inteligencia estadounidense, fue la parte medular del gobierno monárquico que otorgó la información necesaria para reprimir los movimientos sociales que expresaban su repudio al gobierno Pahlevī en tiempos previos a la revolución iraní de 1979. Véase un estudio detallado sobre este cuerpo de seguridad, elaborado por el Comité Central del Partido de las Masas (Tudeh), en Hizb-I Tūdah-'i İrān, Shab’s Secret Police, París, Central Committee of Tudeh-Party of Iran, 1976, p. 18. 
hedin establecieron con líderes palestinos de al-Fatah, organización que contaba con algunos responsables en Dubai, Qatar y Siria, lugares donde llegarían los primeros emisarios de los moyähedin, en $1970 .{ }^{15} \mathrm{Y}$ es que la articulación de intereses con "la revolución palestina" tenía un gran simbolismo para la organización iraní, pues muchos de sus líderes se sentían identificados con ella y con su forma de lidiar contra el sionismo, otro de los agentes del imperialismo mundial y con quien el shab de Irán tenía excelentes relaciones, especialmente de carácter militar, lo cual llamó la atención de la organización para entablar lazos ideológicos y causas de lucha compartidas. ${ }^{16}$

A pesar de esta preparación, no serían los moȳāhedin quienes iniciarían la actividad militar de la denominada "guerrilla iraní”, pues el 8 de febrero de 1971, en Siahkal, Gilan, se perpetró un atentado de un grupo marxista, los Fedā'iyān-e Jalq, contra un puesto de la gendarmería real, por un lado, y un robo a mano armada contra el embajador de Estados Unidos por una pequeña organización llamada Sāzmān-e Rahāì Bajsh, con sede en Teherán, por el otro; eventos que aceleraron las actividades de los moȳähedin, quienes pensaron inmediatamente en dar su primer asalto mediante el boicot a la celebración de los 2500 años de la monarquía iraní, en agosto de 1971, acto que, sin embargo, fue totalmente frustrado por agentes de la Savak, quienes encarcelaron a muchos líderes de la organización. ${ }^{17}$

La reacción de la monarquía ante dichos sucesos fue una dura represión policial, así como una violación masiva a los dere-

${ }^{15}$ Sāzmān-i Mujāhidīn-i Khalq Iran, Sharḅta'sīswa-tārīkhỉ dāth munazzamat mujāhidī al-Sh'ab al-irānī min 'āmm 1965 wa-hatt'a'āmm 1971 [Ëxplicación básica e historia de la Organización de los Moȳāhedīn-del pueblo iraní del año 1965 al año 1971], Berkeley, al- Munazzamah, 1985, pp. 54-62.

${ }_{16}$ Sobre este punto, véase Mu'assasah-'Imutāla'āt va Pizhūhish'hā-yi Siyāsī (Iran) [Instituto de Estudios e Investigaciones Políticas de Irán], Sāzmān-i mujāhidīn-i khalq: Paydāyà tā farjām, yald-e dovom (2). 1344-1384 [La organización de los Moȳāhedīn-e Jalq-e Iraq: auge y declive, volumen II de 1965-2006], Teherán, Mu'assasah-i Muṭāa‘āt va Pizhūhishhā-yi Siyāsī, 2006, p. 393. También, Sazman Muyahidin-e Khalq-e Iran, "Didarba Abu Amar" [el encuentro con Abu Omar], Mojahed, núm. 6A (1359), 1979, pp. 1-4; hay un video en YouTube (www.youtube.com/watch? $=65 x p v m C s m-c)$ donde se muestra el encuentro entre Abu Omar (Yasser Arafat) y los líderes de la Revolución. En esa época todavía la organización era muy cercana a Jomeini.

${ }^{17}$ S. Shahsawandi, "Risheya bivatahulatba'd sazman mojahedin-e khalq (3) goftegu lotfollah meysami ba said shahsawandi” [Las raíces y desarrollo de la organización de los moyahedin-e jalq (3). Diálogo entre lotfollah meysami y saidsahsawandi], manuscrito, 2012. 
chos humanos de jóvenes universitarios. Esta situación permanecería hasta finales de 1977, cuando los moȳāhedìn comenzaron a atacar empresas y ciudadanos estadounidenses, mientras otras organizaciones islamistas levantaban al pueblo iraní en diversas partes del país con un discurso religioso. Entre estas últimas organizaciones estaba la Organización de Clérigos Combatientes, que graduaba a figuras fundadoras del posterior Partido de la República Islámica; entre ellos, Muhammad Bahonar, Muhammad Husein Behesti, Ali Jamenei, Ali Hashimi Rafsanyani, Musavi Ardebili, y Mir Husein Musavi.

Las protestas continuaron durante cuatro meses, hasta que una huelga general, en octubre de 1978, paralizó las refinerías de petróleo. Aquel día se conoce en la historia contemporánea iraní como el "Viernes Negro de 1978" por la dura represión con la que la huelga fue atacada, hecho que dio inicio a la debacle militar, social y política de la monarquía. Los lemas en las calles de los grupos de izquierda cambiaron de una actitud pacífica a una violenta, entre ellos, "Mi kosham mi kosham har ke baradaram kasht" (Mataremos a cada uno que haya matado a un hermano nuestro), ${ }^{18}$ en el contexto de una época donde los líderes de la organización alcanzaron una gran popularidad debido a su efectividad militar contra los agentes de la Savak.

Ya en la ola revolucionaria, la organización abrió oficinas de representación en Tabriz, Mashad, Shiraz, Yazd, Kashan y Rasht, y dejó su cuartel general en Teherán al proclamar un número aproximado de 100000 simpatizantes aunados a las cerca de 9000 víctimas desde su fundación. Las actividades de propaganda (tabliggatt) se intensificaron tras el regreso de Jomeini al país, en febrero de 1979, mientras que Rayavi lo reconocía como "líder indiscutible" (rabbar-e 'enqelāb) de la revolución, y cuando personajes como el ayatola Beheshti se animaban a decir que la revolución descansaba en tres pilares; a saber: Jomeini, Shariati y los Moȳāhedīn-e Jalq-e Iran. ${ }^{19}$

${ }^{18}$ Ahbare Iran, "17 Shahrivar Salgarde Koshtare Mardom Tawassote Regime Shah" [Viernes, 8 de septiembre de 1978, viernes negro, represión del régimen del shab], video subido a YouTube por Hambastegui Meli el 7 de septiembre de 2011.

${ }_{19}$ Abrahamian, Radical Islam, op. cit., p. 76. 


\section{La ruptura con la República Islámica de Irán y la alianza con Iraq}

La articulación de intereses entre los moȳāhedin y los líderes de la revolución estaba encaminada a ganar el favor de Jomeini para asegurar un lugar en la naciente estructura estatal, dado que además se contaba con el apoyo incondicional de Mahmud Taleqani, Mehdi Bazarĝan y, muy pronto, con el de Abolhassan Bani Sadr, primer presidente de la República Islámica de Irán.

El plan de la organización en estos momentos era pedir la disolución de las fuerzas armadas de la monarquía para erigirse como el ala armada del nuevo Estado iraní y así garantizar su supervivencia dentro del Estado. Desde la perspectiva de la República Islámica, esta solicitud no era más que un plan de "inserción y traición”, en el que los moȳähedīn, una vez en control del ejército, avanzarían con una estrategia de sabotaje y golpista contra Jomeini, por lo que, entonces, "institucionalizar las armas a través de una organización como aquella" significaba "ponerse una soga al cuello", sobre todo si los moȳāhedin eran expertos en "actividades terroristas y manipulación de masas". ${ }^{20}$ Por su parte, la organización pensaba que sólo las armas y el desmembramiento del ejército regular les daría cierto poder de negociación en caso de ser marginados del gobierno a manos de los hezbollabi. ${ }^{21}$

Si lo anterior era verdad, entonces el caso de los moȳāhedin sería uno de los más preocupantes para el gobierno de Jomeini por la cantidad de armas y contactos que habían cosechado en

${ }^{20}$ Mu'assasah-'Imutāla‘āt va Pizhūhish'hā-yi Siyāsī (Irán), Sāzmān-i mujāhidīn-i khalq, op. cit., pp. 295-315.

${ }^{21}$ Hezbollabi fue el nombre que recibió todo aquel joven proveniente de diversas provincias del país que, protegido por Jomeini, fue fundamental en la Revolución Cultural Islámica, un proceso posterior al derrocamiento del shab de Irán que consistió en luchar y amedrentar a los secularistas y modernistas en las universidades del país, esto por el temor a que la formación de los jóvenes iraníes "se contaminara de la educación occidental". Los hezbollabi (partidarios de Dios) no llevaban un uniforme específico, pero se dice que eran reconocibles por la gente con un "vistazo" a su barba y manera de vestir. Eran un grupo que ejecutaba las órdenes del gobierno recién llegado, con un alto fervor y apoyo hacia Jomeini y su aparato gubernamental. Gran parte de estos jóvenes se alistaron posteriormente en las fuerzas armadas de la República Islámica para enfrentar la guerra contra Irán a lo largo de la década de los ochenta. Véase S. Bakhash, The Reign of Ayatollahs: Iran and the Islamic Revolution, Nueva York, Basic Books, 1984, pp. 122-123. 
los primeros meses de 1979, cuando tuvieron acceso a información relevante que utilizaron para negociar su posición en la revolución islámica, tal como ocurrió en la denominada crisis de los rehenes. ${ }^{22}$

La desconfianza entre ambos actores influyó en la creación de los pāsdärān, un cuerpo de seguridad independiente tanto de los moyāhedin como del ejército regular de la monarquía (Artesh), que justificó su existencia, por un lado, debido a la necesidad de enfrentar la amenaza externa proveniente de Iraq y, por el otro, por la necesidad de contar con gente de confianza para reprimir y desmantelar a los grupos marxistas dentro del país. Así, estos dos elementos dieron pie a una militarización de la política iraní que no sería llevada cabo por nadie que no fueran los pāsdārān ${ }^{23}$ lo que desembocó en el desencanto de los moȳähedìn y un conflicto retórico y armado entre ellos y la nueva fuerza militar iraní.

El conflicto creció cuando la organización comenzó a señalar a los pāsdārān como "un cuerpo de reaccionarios" que intentaban monopolizar la violencia y la información de los periódicos del país, ${ }^{24}$ a lo que la República Islámica respondió, en la voz del propio Jomeini, refiriéndose a los moȳähedīn como unos "hipócritas" (monāfeqin) "que habían corrompido su visión del islam con ideas eclécticas provenientes del extranjero y se habían convertido en los enemigos más peligrosos del país, incluso más peligrosos que los llamados käfer". ${ }^{25}$

A partir de este momento, los moȳāhedin dedicaron todos sus esfuerzos a equiparar al régimen Pahlevī y al Partido de la República Islámica, mientras Jomeini los comparaba con los califas de la dinastía Omeya. ${ }^{26} \mathrm{El}$ conflicto creció y se materializó

${ }^{22}$ Véanse detalles de este asunto en S. Zabih, The Left in Contemporary Iran: Ideology, Organization, and The Soviet Connection, Londres, Hoover Institution Press, 1986, pp. 48-51.

${ }^{23}$ M. Garduño, "Le modèle des pāsdārān-artesh: préoccupations internes et défis externes dans le cadre du printemps arabe", Maghreb-Machrek, núm. 214, invieno de 2012, p. 73.

${ }^{24}$ Sazman Muyahidin-e Khalq-e Iran, "Oiandeh enqelab” [La revolución que viene], Mojahed, núm. 4 A (11 Bahman 1358), 31 de enero de 1980, pp. 1-3.

${ }^{25}$ S. Arjomand, After Khomeini: Iran under his Successors, Oxford, Oxford University Press, 2009, pp. 23-24.

${ }^{26}$ Sazman Muyahidin-e Khalq-e Iran, "Mayiraha-ye pishtparde-ye grugaangiri” [La historia detrás de la crisis de los rehenes], Mojahed, núm. 102 (2 Dey 1359), 23 de diciembre de 1980, p. 2. 
en una guerra declarada en pleno contexto de la denominada “revolución cultural”, donde el periódico de la organización fue censurado, sus instalaciones editoriales fueron saqueadas y sus manifestaciones rotundamente reprimidas, con la del 20 de junio de 1981, conocida como la "Marcha del 30 Jordād", como una de las más multitudinarias, pero también la más sangrienta tras la revolución.

A una semana de los altercados, la organización intentó asesinar al actual líder supremo iraní, Ali Jamenei, a quien en medio de un acto público le dirigieron un par de tiros e hirieron en un brazo. ${ }^{27}$ Posteriormente, la organización lanzó otro ataque en contra de la sede central del Partido de la Revolución Islámica, el 28 de junio, ataque conocido en la prensa internacional como el Hafteh Tìr bombing (el bombazo del 28 de junio), el cual sorprendió y asesinó en plena reunión a un total de 120 personas; entre ellos, al mismo ayatola Beheshti, considerado el segundo personaje más influyente después de Jomeini. ${ }^{28}$ Otro golpe se constituyó el 30 de agosto, cuando la organización detonó una bomba en la oficina del Consejo Supremo de Defensa, donde el entonces primer ministro Muhammad Bahonar se reuniría con el presidente Muhammad Ali Rayai, quien tenía pocos meses de haber tomado el puesto. La detonación asesinó a ambos representantes, a otras dos personas y dejó cerca de 14 heridos. ${ }^{29}$

Mientras la organización realizaba más atentados de este tipo, Rayavi y el ya entonces ex presidente Abol Hassan Bani Sadr habían huido a París en un Boeing 707 comandado por el mismo piloto de la fuerza aérea que había sacado al shab del país un par de años atrás (Behzad Moesi), lo que inició el periodo de los moȳähedīn en el exilio. Una vez en Francia, Rayavi

${ }^{27}$ Islamic Media Front, “Assassination Attempt on Ayatollah Khamenei by Munafiqeen-e-Khalq Western Backed Terrorist Organization" [Intento de asesinato de Ali Jamenei por la Organización de los Moyahedin-e Jalq-e Iran apoyada desde Occidente], video subido a YouTube por Islamic Media Front, el 27 de agosto de 2008.

${ }^{28}$ J. Kifner, "Iranian Bomb Deaths could Spark Power Struggle", The Times Neres, 1 de julio de 1981, p. 19.

${ }_{29}$ Aquel ataque fue el más profundo que perpetró la organización y el más mediático, pero no el único. En septiembre, la organización perpetró más ataques suicidas contra un religioso de alto nivel en Tabriz y un líder del Partido de la República Islámica, en Jorasán. Véase también St. Petersburg Times Desk, "Bomb Blast kills Iran's President, Prime Minister”, St. Petersburg Times, 31 de agosto de 1981, p. A-21. 
y Bani Sadr establecieron formalmente el Shūra-ȳe Mellī-ȳe Moqavamat o Consejo Nacional de Resistencia de Irán (CNRI), una organización que pretendía reunir en un solo organismo a la serie de grupos y organizaciones que habían mostrado oposición al gobierno de la República Islámica de Irán y, de cierta manera, simpatía hacia los moȳähedìn. Sin embargo, poco tiempo después, Rayavi echaría a andar una estrategia paralela que consistiría en aliarse con actores opuestos totalmente a Irán, tales como Iraq, lo cual le llevaría a perder popularidad y credibilidad en Irán e, incluso, a perder el apoyo de personalidades como el ex presidente Abolhassan Bani Șadr, quien salió del Consejo en 1982. ${ }^{30}$

$\mathrm{La}$ articulación de intereses con Iraq se inició, en enero de 1983, en la sede del Consejo en Auvers-sur-Oise, París. Ahí se negociaría una alianza político-militar entre Rayavi y Tariq Aziz, entonces primer ministro iraquí; Rayavi presentó el encuentro a la opinión pública como "una negociación para alcanzar la paz con Iraq y garantizar la integridad territorial de ambos países, así como de no interferencia en sus políticas internas", ${ }^{31}$ aunque en la práctica se estaba gestando la creación de un cuerpo militar de los moȳähedin que, totalmente financiado por Sadam Husein, tomó el nombre de Ejercito Nacional de Liberación de Irán (ENLI), brazo que, para finales de 1986, ya se había alineado con Sadam Husein en la guerra Irán-Iraq y trabajaba en el campo Ashraf, un lugar aledaño a Bagdad, que sería ocupado por 3000 soldados moȳähedin autodenomina-

${ }^{30} \mathrm{El}$ Consejo se conformaría también de otros grupos e individuos que hicieron funcionar a esta nueva organización como un "parlamento iraní en el exilio", lo cual estaría estimulado por la aparente debilidad del gobierno de Jomeini que luchaba con la inestabilidad interna generada por los ataques de los moȳähedin, así como con la amenaza externa que planteaba la guerra con Iraq. A su vez, el Consejo incluyó otras organizaciones que ya eran controladas, administradas y adoctrinadas por los propios moȳāhedin; entre estas últimas pueden citarse la Asociación de Estudiantes Musulmanes, la Sociedad de Gremios Tawhidī, el Movimiento de los Maestros Musulmanes, la Unión de Instructores de Universidades e Instituciones de Educación Superior y la Sociedad para la Defensa y la Democracia de Irán. Véase K. Katzman, The People’s Mojahedin Organization of Iran, Washington, Congressional Research Service-Library of Congress, 1992, p. 5.

${ }^{31}$ Foreign Affairs Committee of The National Council of Resistance of Iran, Democracy Betrayed: A Response to U.S. State Department Report on the Mojahedin and the Iranian Resistance, Auvers-sur-Oise, Foreign Affairs Committee of The National Council of Resistance of Iran, 1995, pp. 1-2. 
dos "los liberadores del pueblo de Irán y desde donde se atacaría suelo iraní". 32

Aunque la firma de la paz entre Irán e Iraq llegó, en 1987, mediante la resolución 598 del Consejo de Seguridad de la ONU, ${ }^{33}$ el ejército de liberación siguió atacando suelo iraní hasta 1988 , en un intento por romper la tregua entre Jomeini y Husein, y usó tanques contra la ciudad de Kermanshah, ubicada a sólo 80 kilómetros de la frontera iraquí. ${ }^{34}$ Por su parte, Sadam Husein había decidido invadir Kuwait, el 2 de agosto de 1990, pensando que así podría amortiguar la crisis económica que había dejado la guerra anterior, hecho que dio inicio a la denominada Guerra del Golfo, escenario donde el ejército de liberación actuó nuevamente en favor de Iraq al reprimir rebeliones kurdas, quienes habían aprovechado la intervención de Estados Unidos para mostrar sus aspiraciones autónomas a la comunidad internacional. ${ }^{35}$

Aunque Irán no tomó parte efectiva en la campaña de 1991 contra Iraq como se esperaba, la situación creada en la región a partir del embargo contra Sadam Husein y los primeros indicios de la resistencia armada islamista en la zona, convencieron a la Casa Blanca de la necesidad de mantener una relación abierta y pragmática con Teherán. ${ }^{36}$ De hecho, en esta coyuntura de acer-

${ }^{32}$ Mientras la República Islámica estimaba que el número de reclutas no rebasaba los 3000 efectivos, un comandante del ELNI, Ebrahim Zakeri, cifró la cantidad en 3000 efectivos más 900 prisioneros de guerra, quienes habían jurado lealtad a la organización armada hasta 1987. Véase sobre esto en C. P. Wallace, "Regained 2 Towns in Heavy Fighting, Iranians Report”, Los Angeles Times, 30 de julio de 1988.

${ }^{33}$ Consejo de Seguridad de las Naciones Unidas, "Resolución 598 del 20 de julio de 1987".

${ }^{34}$ Los ataques contra la población civil iraní se dieron en julio de 1988 a través de la operación "Luz Eterna”, lo cual restó a los moȳāhedin apoyo, simpatía y credibilidad en Irán y propició que comenzara a desvanecerse de su buena reputación entre las clases universitarias y comerciantes iraníes.

${ }^{35}$ Human Rights Watch, Endless Torment: The 1991 Uprising In Iraq and its Aftermath, Nueva York, Human Rights Watch, 1992.

${ }^{36}$ Así, y al igual que Siria en aquel momento, el gobierno iraní demostró su utilidad cuando permitió a Estados Unidos actuar militarmente contra los talibanes y las actividades de Osama Bin Laden en Afganistán. Luego, Teherán hizo lo que pudo para moderar los ímpetus de la oposición shi'ía iraquí e, incluso, medió para que parte de ella se sumase de un modo u otro a la estrategia estadounidense, que incluía programas tales como el de Petróleo por Alimentos. A cambio, Teherán pidió la deportación de los moȳāhedin a Irán, hecho que no se consumó porque no había herramientas jurídicas suficientes para hacerlo (Sadam aún estaba en el poder en Iraq), 
camiento entre Estados Unidos e Irán, un informe elaborado por el experto en Irán Kennet Katzman documentaba, en 1992, que "tanto el CNRI, el ELNI y los moȳāhedin eran una misma organización que había cometido varios actos de terrorismo donde también habían perecido algunos ciudadanos estadounienses", ${ }^{37}$ lo que dio pie a la designación de los moȳähedin como una organización terrorista, formalmente en 1997, acto que replicó la Unión Europea, en 2002, bajo argumentos y procedimientos similares.

Sin apoyo del pueblo iraní, con la mala reputación de su aliado iraquí y con la designación de terrorismo internacional por Estados Unidos y la Unión Europea, ciertamente parecía el final de la organización apenas comenzado el siglo xxi y el fin de los moȳābedin como grupo de oposición iraní.

\section{Los moȳähedin ante la invasión estadounidense a Iraq, en 2003, y el programa nuclear iraní}

Pero los moȳābedin se resistían a desaparecer como actor político pues echarían mano de una nueva articulación política al tender los primeros lazos hacia los mismos enemigos de su antiguo aliado iraquí, es decir, hacia el gobierno de Washington.

Ante la aguda crisis que propició el régimen de sanciones a Iraq, la organización inició una "revolución cultural interna" para evitar que sus miembros cuestionaran las decisiones de sus líderes. Se desarrolló un culto a las personalidades de Masud y Mariam Rayavi (su esposa) que devino en un estricto control de los miembros y en algunos cambios en la forma de organización interna. ${ }^{38}$

por lo que el gobierno iraní, ya con Rafsanyani al mando, tuvo que esperar otro tipo de gesto positivo al respecto.

${ }^{37}$ Katzman, The People's Mojahedin Organization of Iran, op. cit.

${ }^{38} \mathrm{El}$ inicio de este proceso está marcado por el matrimonio entre Masud Rayavi y Mariam Ażodanlu (quien a partir de entonces tomó el apellido de su esposo y era conocida como Mariam Rayavi), y se presentó como "algo necesario e inevitable que conduciría a una convivencia pacífica en la organización” y que elevó a Masud Rayavi a la calidad de líder político y espiritual. Estos cambios incluirían, en principio, el matrimonio sólo con miembros de la organización "para evitar la contaminación de ideas externas" o, en el mejor de los casos, el celibato, que significaría un acto de sacrificio de las necesidades sexuales para así aumentar la eficiencia de las personas 
Este adoctrinamiento interno era necesario para enfrentar cualquier crisis externa a los moȳähedinn, ya que como organización terrorista tenían muy poco margen de maniobra para lograr una nueva articulación de intereses, como las alcanzadas previamente. Además, con el ascenso de Muhammad Jatami a la presidencia iraní, en 1997, se abrió un nuevo periodo geopolítico, en el cual la política exterior de Teherán se caracterizó por su diplomacia que compatibilizaba islam y democracia, y por el inicio de un proceso de distensión con Estados Unidos en la región del Golfo Pérsico, al menos hasta el inicio de "la guerra contra el terrorismo" que inauguró George W. Bush, en 2001, particularmente después del 11 de septiembre. ${ }^{39}$

Y es que, justamente, dos acontecimientos -el 11 de septiembre de 2001 y el anuncio del programa nuclear iraní, en 2002 - cambiaron el panorama geopolítico de la región, pues favorecieron la posición de los moȳähedin y perjudicaron la del gobierno iraní. Un efecto de los acontecimientos del 11 de septiembre fue la proclamación, por George W. Bush, del denominado "eje del mal"; mediante un discurso en enero de 2002, incluyó a Teherán como parte de dicho bloque, junto con países como Iraq y Corea del Norte, lo que dio inicio a la denominada "guerra contra el terrorismo". ${ }^{40}$

En este marco se inserta el anuncio de los moȳähedin, el 14 de agosto de ese mismo año, mediante una conferencia de pren-

\footnotetext{
y su dedicación plena hacia sus labores. Además, todos y cada uno de sus miembros fueron exhortados a escribir reportes a diario sobre sus pensamientos, ideas y deseos; reportes que eran conocidos como neshest (reuniones) y que también consistían en una serie de ideas que cada miembro tenía que dar a los mas ${ }^{5} l$ (guardianes o responsables) de su grupo para ser discutidas en público, en sesiones que duraban el tiempo necesario para ser juzgados y pedir perdón en el nombre del líder. Así, se otorgaba un elemento de cohesión interna y total dedicación al grupo, y los cuestionamientos, las dudas y las críticas no cabían más dentro de la estructura organizativa a la que la mayoría de los miembros habían dado su vida entera. Véase R. Cohen, The Rise and Fall of the Mojabedin Khalq, 1987-1997: Their Survival after the Islamic Revolution and Resistance to the Islamic Republic of Iran, Brighton, Sussex Academic Press, 2009, p. 40.

${ }^{39}$ A. A. Rezaei, "Foreign Policy Theories: Implications for Foreign Policy Analysis of Iran”, en Anoushiravan Ehteshami y Mahjoob Zweiri (eds.), Iran's Foreign Policy: From Khatami to Abmadinejad, Berkshire, Ithaca Press, 2008, p. 17. Véase también L. Mesa, El debate sobre la seguridad nacional en la República Islámica de Irán: estudio del primer mandato del presidente hojatoleslam Seyed Mohammed Khatami (1997-2001), México, El Colegio de México, 2009, p. 56.

${ }^{40}$ G. W. Bush, "State of the Union Address", Washington, Office of the Press Secretary, 29 de enero de 2002.
} 
sa de un simpatizante de nombre Ali Reza Yafar Zadeh, quien afirmaba tener "pruebas fehacientes de que Irán tenía un programa secreto para desarrollar armas nucleares" y que dicho plan "constituía una grave amenaza a la seguridad regional e internacional". ${ }^{41}$

La noticia de esa conferencia le dio la vuelta al mundo, aunque no toda la información solicitada en la ronda de preguntas y respuestas fue consistente con la inquietud de la prensa. Un punto en tela de juicio fue, por ejemplo, la capacidad real que los moȳähedin tenían para ofrecer imágenes por satélite, como las que aquella mañana ofreció Yafar Zadeh, quien ante dicho cuestionamiento explicó: "Bueno, ahora todos, cualquiera de nosotros, tiene acceso a un satélite, pero nosotros no necesitamos satélites para saber quién propaga el terrorismo y las armas de destrucción masiva en el mundo". ${ }^{42}$ La respuesta no convenció del todo a especialistas y reporteros, sobre todo porque se trataba de material que fue resultado del uso de tecnología de punta para enfocar sitios nucleares secretos, imprimir a detalle sus imágenes y guardar tajantemente direcciones de lugares y nombres de expertos que trabajaban en aquella construcción, todas labores dignas de una agencia profesional de inteligencia.

$Y$ aunque la mayor parte de la información en años subsecuentes no pudo comprobarse, Irán aceptó la existencia de los sitios de Arak y Natanz, anunciados por Yafar Zadeh, en 2002. El punto importante en este aspecto era saber quién o quiénes habían proporcionado a los moȳābedin la tecnología para obtener esas imágenes, ya que era claro que ellos, en época de crisis además, no tenían los medios ni los conocimientos tecnológicos para dar con esos lugares. La organización era un grupo estrictamente militar que se especializaba en los golpes terroristas y en la inteligencia en campo, y por estas razones no tenía la experiencia ni el adoctrinamiento para manejar la tecnología satelital que fue usada para presentar las imágenes que destaparon los lugares secretos que Irán tuvo que aceptar.

Que el material de los moȳāhedin hubiera sido tomado por ellos mismos a través de estudios e investigaciones en campo

${ }^{41}$ Jafarzadeh, The Iran Threat, op. cit., p. 12.
${ }^{42}$ Ibid., p. 34. 
o por tecnología satelital sigue siendo muy dudoso, aunque en aquellos años fue muy conveniente para la organización el autoerigirse y reinventarse como una fuente de información y de inteligencia para los enemigos regionales y extrarregionales de la República Islámica de Irán. En este sentido, un ex miembro de los moȳähedin, que hasta 1996 era el encargado de las comunicaciones y la seguridad de la organización con sede en Bagdad, Masoud Jodābandeh, menciona que los moȳāhedīn:

\begin{abstract}
[...] no tiene [sic] satélites para vigilar los sitios secretos militares iraníes [...] lo que pusieron de manifiesto fue solamente las instalaciones que las autoridades iraníes han creado para el enriquecimiento de uranio y que no habían informado a la Agencia Internacional de Energía Atómica [...] fueron los estadounidenses y los israelíes los que, de hecho, han puesto de manifiesto las instalaciones de Arak y Natanz y han creado un escenario elaborado por la línea dura del gobierno en el Pentágono para promover el caso de los moȳähedin como una palanca contra la República Islámica de Irán. ${ }^{43}$
\end{abstract}

Sea cual fuere el origen de los documentos que presentaron los moȳähedin a través de simpatizantes en Washington, a partir de entonces "el tema nuclear en Irán" acapararía la atención y sería uno de los más debatidos entre la opinión pública internacional, hecho que ayudó a los moȳähedìn a ganarse la confianza de Washington como "informantes expertos en Irán" y a que comenzara el proceso jurídico para retirarlos de la "lista negra del Departamento de Estado". Hay que recordar que la invasión a Afganistán ya estaba en marcha y las amenazas y sanciones a Iraq estaban surtiendo efecto y sirviendo como un preámbulo para su invasión, en marzo de 2003.

Cuando finalmente llegó el desarme de Sadam Husein, una serie de estereotipos se estaban gestando en contra de la imagen del musulmán, y del árabe en particular, de quien se pretendía fuese visto como un sinónimo de terrorista o fundamentalista, lo cual sería aprovechado por los moȳähedin para venderse como un ejemplo de "islam progresista", "verdaderamente compatible con los valores occidentales, como la democracia y la universalidad de los derechos humanos". Así, comenzó formalmente una articulación de intereses con Washington que inclui-

${ }^{43}$ Ebrahim Jodābandeh, comunicación personal vía Skype, 1 de julio de 2012. 
ría el anuncio público de dejar las armas y una campaña legal para ser eliminada de la lista de organizaciones terroristas extranjeras del Departamento de Estado, mientras, por otro lado, se iniciaba un programa de entrenamiento secreto, con ayuda de Washington, en campos militares de Nevada, de acuerdo con algunas fuentes. ${ }^{44}$

\section{Los moȳäbedin y el reformismo en Irán: el caso del Movimiento Verde}

En este contexto se tiene que hablar del advenimiento de Mahmud Ahmadi Neyad a la presidencia iraní, en 2005, la cual vino acompañada de una generación de veteranos de guerra que ocupó algunos cargos importantes dentro del sistema político iraní. Esto es importante porque en ese año comenzaría una nueva relación de poder entre Irán y Estados Unidos, donde pudo apreciarse una retórica de "mutua demonización” que resultaría en un nuevo distanciamiento entre ambos países y en un respiro para los moȳāhedīn, que vendían la idea de que el enemigo de la región no había sido el Iraq nacionalista de Sadam Husein sino su antiguo enemigo, el gobierno islamista de Irán.

La militarización del gobierno iraní aceleró las sospechas de las potencias occidentales de que el programa nuclear nacional estaba dirigido hacia planes bélicos, tal como lo señalaban los moȳāhedin, a pesar de la negación del asunto por el gobierno de Ahmadi Neyad, y su justificación del enriquecimiento de uranio para fines médicos. ${ }^{45}$ Ante esto, los líderes de la organiza-

${ }^{44} \mathrm{Al}$ momento de ser desarmados por el ejército estadounidense en plena invasión a Iraq, los miembros de la organización fueron catalogados como "personas protegidas" (y no como prisioneros de guerra, una figura jurídica que se otorga a las organizaciones terroristas en escenarios de guerra), lo que representó una maniobra misteriosa de Estados Unidos en Iraq en relación con este grupo. S. Hersh, "Our Men in Iran?”, The New Yorker, 6 de abril de 2012.

${ }^{45}$ Además, las declaraciones del presidente iraní del 25 de octubre de 2005, "sobre la necesidad de que el "régimen que ocupa Jerusalén se desvaneciera en el tiempo" (Imām goft ke īn reȳim-e ishjal gar-e qods bāyad az safheh-ȳe ruzeĝar mahv shavad), causaron alerta máxima en Israel sobre el asunto, activaron toda una maquinaria mediática para descalificar a Irán sobre sus intenciones nucleares, y provocaron una crisis de confianza que llevó a Irán a ser sujeto de sanciones económicas en los sectores bancarios, militares e industriales del país. M. Ahmadinejad, "Yahan bediun sihiunism" [El mundo sin sionismo], video subido a YouTube por Shahid Witness, el 26 de septiembre de 2012. 
ción comenzaron a trabajar en una imagen conciliadora de su plataforma ideológica, mientras que la prensa crítica los ubicaba como colaboradores de Israel en el asesinato selectivo de científicos iraníes expertos en cuestiones nucleares. ${ }^{46}$

Entre las múltiples estrategias que Mariam Rayavi intentó para graduar al Consejo Nacional de Resistencia de Irán como una organización independiente, conformada por miembros de varios sectores de la sociedad iraní, está la organización de mítines, reuniones y protestas en las que supuestamente el grupo logra reunir a "miles personas" en cada una de sus presentaciones, a lo largo de ciudades estadounidenses y europeas. ${ }^{47} \mathrm{Sin}$ embargo, de acuerdo con algunas encuestas recientes, como la realizada en abril de 2013 por la George Mason University, entre los iraníes que radican en Estados Unidos los moȳāhedīn ocupan el último lugar de preferencias, por debajo, incluso, de la popularidad que tiene el hijo del depuesto shah de Irán de la dinastía Pahlevī, y donde la plataforma del Movimiento Verde (Yanbesh Sabzī) lidera las preferencias de los iraníes en suelo estadounidense. ${ }^{48}$

Para hablar del Movimiento Verde es necesario mencionar las protestas en Irán de 2009, un acontecimiento nacido en medio de la crisis nuclear que es considerado como el movimiento contestatario más grande del país después de la Revolución islámica de $1979 .{ }^{49}$ Estas protestas se prolongaron hasta febrero

${ }^{46}$ R. Silverstein, "Israeli Source: Assassination of Iranian Nuclear Scientist Joint Mossad-мек Operation”, página web de Richard Silverstein, 10 de enero de 2012.

${ }^{47}$ Aquí hay que señalar que las fuentes de financiamiento de la organización comenzaron a depender de una serie de grupos y sociedades iraníes en el exilio que tienen familiares en Campo Ashraf, luego de su abandono, en 2013, en el Campo Liberty, el nuevo refugio de la organización. Los familiares mandan dinero proveniente de una serie de negocios de alfombras, joyas y automóviles en diferentes partes de Europa, principalmente Berlín, París y Londres. Véase sobre el tema del financiamiento, con más detalle en Estados Unidos, Inglaterra, Francia y Alemania, M. Garduño, "La articulación de objetivos...”, op. cit., p. 521.

${ }^{48}$ Las protestas en Teherán fueron multitudinarias debido al malestar que causó el presunto fraude electoral, donde Ahmadi Neyad, en aquellos años, comenzaba a experimentar los estragos de una crisis económica, resultante no sólo de las sanciones económicas internacionales, sino también de los métodos populistas utilizados por el presidente para mantener y ampliar su base social. Public Affairs Alliance of Iranian Americans (PAAIA), 2013 National Public Opinion Survey of Iranian Americans, Washington, comisionada por PAAIA y llevada a cabo por la George Mason University, 2013, p. 27.

${ }^{49}$ Fue a partir de 2010 cuando Irán comenzó a diversificar su comercio con Chi- 
de 2011 y se conectaron con el surgimiento de las revoluciones árabes, episodios que han querido ser aprovechados por los moyähedin para lograr apoyo internacional, al buscar que su causa, el derrocamiento del régimen iraní", se relacionara con la ola de dictadores árabes que estaban en tela de juicio en países del Norte de África y aprovechar con ello la mala reputación del gobierno iraní en los medios de comunicación oficiales. ${ }^{50}$

Lo anterior puede conducir a algo que diferencia claramente a los moȳāhedin del Movimiento Verde. Como es conocido, el descontento entre los jóvenes iraníes tras los resultados electorales de junio de 2009 fue contenido con una severa represión del gobierno iraní, particularmente en Teherán. En una de tantas declaraciones de intelectuales que favorecen al gobierno iraní, Mohamed Marandi51 trató el tema: "los miembros de la organización de los moȳähedìn habían incitado a la violencia en las calles aquel 13 de junio de 2009 y son responsables, incluso, hasta de las protestas de febrero de 2011 (bahman), que dejaron decenas de muertos y miles de heridos y detenidos en la capital". ${ }^{52}$ Pero estas declaraciones le daban más importancia y propaganda a la organización de lo que sus capacidades de movilización social en Irán le permitían hacer. Contrario a adjudicarse la responsabilidad de las movilizaciones (lo cual hubiera representado una espléndida muestra de poder dentro de Irán), Mariam Rayavi se limitó a señalar el fraude electoral y a condenar la negativa de las autoridades a anular los resultados de las elecciones presidenciales de aquel año. Además, describió la situación como una crisis y un "terremoto político" dentro del "régimen", al decir que "Jamenei había cometido un error garrafal al insistir sobre la ridícula cifra de 40 millones de votos en

na, India y otros países de Asia Central. Las sanciones económicas impuestas en 2010 fueron sorteadas, por ejemplo, con empresas rusas, chinas, malasias y turcas. Véase al respecto Luciano Zaccara, "Irán y EEUU: ni sanciones ni intervención”, Estudios de Política Exterior, núm. 139, enero-febrero de 2011, p. 6.

${ }^{50}$ Clifford, The Marketing of Rebellion, op. cit., pp. 1-22.

${ }^{51}$ Marandi es un graduado de la Universidad de Birmingham y profesor asociado de inglés y literatura en la Universidad de Teherán. Es el fundador y director del Instituto de Estudios de América del Norte y Europa. Nació en 1966, en Richmond, Virginia, es el hijo del ex ministro iraní de Salud y miembro del parlamento, Alireza Marandi, y un defensor sólido de la República Islámica y su líder supremo.

52 Press TV, "Musavi backed by Terror Group: Scholar", Press Tv Newes, 7 de marzo de 2011. 
las elecciones a favor de Ahmadi Neyad, y ahora tenía que mostrar el arma de la represión del levantamiento popular". ${ }^{53}$

Y mientras "los terroristas" y "el régimen" se demonizaban mutuamente, el movimiento social que realmente comenzó las movilizaciones alcanzaba una identidad más sólida, pues logró ganarse un nombre de referencia en los medios de comunicación y tener líderes visibles, quienes serían puestos en arresto domiciliario poco tiempo después de refutar los resultados oficiales. ${ }^{54}$ El Movimiento Verde, a diferencia de los moȳähedìn, exportó el eslogan “Rāy-e man koyāst?" (¿Dónde está mi voto?) que cantaron decenas de miles de ciudadanos en Teherán, y tardó poco tiempo en mandar una señal clara y contundente sobre su posición respecto de los moȳähedin en uno de los sitios de Internet más utilizados por sus líderes reformistas (de hecho, atribuido a uno de ellos, Mir-Husein Musavi), donde asentaba que "el movimiento no tenía vínculo alguno con los moȳähedinn, ya que se trataba, por el contrario, de un símbolo de terror y traición a la sociedad iraní. ${ }^{55}$

Así, la plataforma del Movimiento Verde ha sido coreada en las calles de Teherán y otras ciudades a pesar de la represión policial y paramilitar de la que fueron víctimas sus ciudadanos, mientras que la plataforma de los moȳāhedin es repudiada y condenada públicamente. Al hacer referencia a la organización, MirHusein Musavi tomó la postura consensuada entre los jóvenes universitarios iraníes, principales propulsores del movimiento de reforma en Irán, de que era "un paria", no sólo para distanciarse de ella, sino también para señalarla como integrada por "terroristas y traidores a la patria" y "una organización que ha optado por la sumisión a las potencias extranjeras", a las que se ha mostrado que "la resistencia en Irán se ha convertido en el ejemplo de la resistencia no violenta, de la lucha contra la dic-

${ }^{53}$ People’s Mojahedin Organization of Iran, “june 2009 peyam e Maryam Rajavi baraye nedaye azadi e mardome iran" [Mensaje de Maryam Rajavi sobre las muestras de liberación del pueblo de Irán], video subido a YouTube por Khorshid Asadi, el 24 de junio de 2009.

${ }^{54}$ Ministerio del Interior de Irán, "Resultados oficiales de la elección presidencial iraní 2009”, Teherán, 2009.

${ }^{55}$ Kalemeh, "Moȳāhedīn-e Jalq: nemād va ebstegījashvanat va turūd dar Irān" [Moȳāhedīn, un símbolo del terror y la violencia en Irán], Kalemeh (1390), 14 de agosto de 2011. 
tadura y la independencia de otros países, sin aceptar la violencia y la sumisión, y sin ver con buenos ojos cualquier tipo de agresión militar en contra del país". ${ }^{56}$

Ciertamente es claro que el Movimiento Verde iraní rechaza categóricamente cualquier vínculo con los moȳāhedin y está más en armonía con las demandas de los movimientos vistos en las revoluciones árabes, cuando cantan el término refolución (mezcla de revolución y reforma); mientras, el gobierno iraní insiste en que ambos movimientos son exactamente lo mismo, y busca criminalizar la protesta en Irán, tal como lo hace la mayoría de los regímenes poscoloniales a los que la llamada "Primavera árabe" se ha enfrentado.

$Y$ es que el gobierno iraní ha insistido en explotar la mala reputación que los moȳāhedinn tienen entre la población iraní, para fines políticos y para lastimar la imagen del Movimiento Verde. En las calles de Teherán, por ejemplo, hubo momentos entre 2009 y 2010 donde se observaron fotografías que hacían alusión a una supuesta relación entre Mir-Husein Musavi y Masud Rayavi, y los catalogaban como "los líderes de la sedición”, aunado a toda una campaña de marketing para desprestigiar al Movimiento Verde con supuestas relaciones y vínculos con los "terroristas hipócritas de los moȳāhedīn". ${ }^{57}$ Incluso, ante la muerte, en diciembre de 2009 , de uno de los ayatola más prestigiosos del establishment religioso de la shía iraní, ayatola Montażeri, nuevamente el intelectual simpatizante del líder supremo, Muhammad Marandi, declaró: “el ayatola Montażeri había dejado de ser un gran jugador político en la escena iraní desde que se descubrió que su círculo más íntimo estaba ligado a los moȳähedīn; en ese momento, los reformistas lo aislaron y perdió potencial político en la nación". ${ }^{5}$

Si bien es sabido que el ayatola Montażeri apoyó a los moyābedin en su época de esplendor, no se supo más de ese apoyo cuando los moȳähedin eran comandados por los rayavī, y mucho menos a sabiendas de que habían recibido el apoyo iraquí

${ }^{56}$ Idem.

${ }^{57}$ M. Sinaiee, "Iran Hardliners pledge to oust 'Leaders of Sedition'”, The National, 9 de enero de 2011.

${ }^{58}$ Al Jazeera Desk, "Iranians Mourn Dissident Cleric", Al Jazeera, 21 de diciembre de 2009. 
durante la década de 1980 o el apoyo de Estados Unidos ante una hipotética confrontación bélica entre Washington-Tel Aviv y Teherán. La asociación que hace Marandi de los moȳähedinn con Montażeri parece ser parte de la estrategia que el gobierno iraní ha usado para desprestigiar a los líderes reformistas que buscan reconfigurar las políticas nacionales, por medio no de una revolución sino de transformaciones válidas para todos los sectores de la sociedad y que no buscan derrocar el sistema de gobierno de la República Islámica como lo pretenden los propios moȳähedin. Videos en las redes sociales que apoyan esta tesis reviven lo acontecido en la conmemoración de la muerte de Montażeri, al clamar eslogans como "El movimiento no para, seguirá contra tus mentiras de 68\%" (en alusión al supuesto $68 \%$ de los votos obtenidos por Ahmadi Neyad) y otros lemas que retomarían Mir-Husein Musavi y otros líderes del movimiento, que repetirían su distanciamiento de la organización, tales como el intelectual religioso y activista Mohsen Kadivar, ${ }^{59}$ quien afirma: "el gobierno con tal de desacreditar al Movimiento Verde es capaz de revivir a los moȳähedin para reprimir a cualquier sospechoso". ${ }^{60}$

Con relación al proceso de las revoluciones árabes, la praxis política de los moȳähedin refleja una notable maniobra de alineación con las grandes potencias y sus labores contrarrevolucionarias, más que con los movimientos contestatarios que derribaron a algunos dictadores del Norte de África y el Medio Oriente. Y es que los moȳähedin han gastado sus esfuerzos en anunciar "el pronto colapso sirio e iraní, tal como aconteció con el colapso de los regímenes egipcio, libio y tunecino, ${ }^{61} \mathrm{al}$ atacar y criticar exclusivamente a los pāsdärān y a los basīyì en su ola represiva contra el Movimiento Verde, mientras, por otro lado, guardan silencio respecto de lo ocurrido contra otros

${ }^{59}$ Kadivar nació en 1959 y es un filósofo iraní, profesor de universidad, hombre de religión y activista. Se trata de un disidente político y fuerte crítico de la doctrina del gobierno iraní actual. Se considera un firme defensor de las reformas democráticas y liberales en Irán. Ha estado en prisión en Irán por su activismo político y sus creencias.

${ }^{60}$ M. Khadivar y A. Sadri, “Hillary Clinton's Crucial Choice on Iran”, Salon, 26 de marzo de 2011.

${ }^{61}$ Tariq Alhomayed, "He'd be Lucky to share Mubarak’s Fate”, Ashar Al Awsat, 11 de julio de 2012 . 
regímenes "geopolíticamente sensibles", como Arabia Saudí, Qatar y otras monarquías del Golfo Pérsico.

\section{Consideraciones finales}

Después del repaso de las diversas articulaciones de objetivos políticos que la organización ha hecho a través de su historia, puede concluirse que los Moȳāhedīn-e Jalq-e Iran se han mantenido operando como organización política de oposición al gobierno iraní debido a su alianza con actores constituidos como rivales de la República Islámica de Irán, regional e internacionalmente, en diferentes etapas históricas, y no tanto por el éxito en la construcción de sus discursos y narrativa como una organización defensora de los derechos humanos o la democracia, estrategia que ha fracasado por carecer de una base social sólida que apoye dichas reinvenciones y de la credibilidad que sostenga este discurso entre la sociedad iraní.

Tres evidencias pueden ayudar a mantener el argumento anterior, las cuales radican en el relativo éxito que ha tenido su articulación política, económica y militar con diversos personajes, donde ocupa el primer lugar Jomeini, luego Sadam Husein y, posteriormente, la élite conservadora en Washington y algunos países europeos:

1. El eje de articulación de objetivos con Jomeini fue la retórica antiestadounidense, antimonárquica y antiimperialista que ambos actores llevaron a la práctica bajo el eslogan "Morg beh amrikeā" (Muerte a Estados Unidos).

2. En segundo lugar cabe pensar en el uso del eslogan "La liberación de Irán y el derrocamiento de Jomeini” como mecanismo de unión con Sadam Husein, lo cual ocasionó al grupo la pérdida de popularidad dentro de Irán, así como de los principales valores de independencia política que los caracterizaban hasta ese momento.

3. En tercer lugar, ante la erosión del gobierno de Sadam Husein tras la denominada Guerra del Golfo, en 1991, y la invasión de Estados Unidos, en 2003, los moȳähedin echaron mano de una nueva articulación política en favor de la sa- 
tanización de Irán como actor patrocinador del terrorismo internacional. Esto se hizo al lado de los neoconservadores de Estados Unidos y algunos países de Europa, quienes tenían el objetivo de contener la emergencia de Irán como potencia regional en Oriente Medio y frenar el desarrollo de su actual programa nuclear.

Puede decirse que el fenómeno de la articulación ha sido el condicionante atmosférico más influyente en la supervivencia organizacional de los Moȳāhedīn-e Jalq-e Iran, pues es justo señalar que el éxito de las articulaciones ha dependido enormemente del grado de acercamiento y rivalidad que ha tenido Irán con sus competidores regionales e internacionales en diferentes fases históricas, competidores con los cuales los moȳähedin han querido construir un ambiente de confianza que sólo se ha quedado en alianzas militares y políticas coyunturales. Así, por ejemplo, la firma del tratado de paz entre Iraq e Irán, que ponía fin a la guerra de toda una década, significó uno de los momentos más difíciles para la organización, puesto que su principal aliado estaba negociando un cese de hostilidades con Jomeini, quien, en ese contexto, podría haber incluido la deportación de lo que Irán consideraba "una gama de hipócritas y traidores políticos a la patria", lo cual ponía en gran riesgo su propia existencia como actor político de oposición. Otro ejemplo lo constituyó el acercamiento entre los gobiernos de Jatamì y Clinton, en 1997, año en el que los moȳähedin fueron considerados oficialmente como una organización terrorista, bajo los parámetros del Departamento de Estado, e incluidos en la famosa lista negra de organizaciones terroristas extranjeras. En 2012, sin embargo, los moȳähedin fueron eliminados de esa lista por Hillary Clinton (tal como lo hizo la Unión Europea en 2009), después de un largo litigio que ganaron con el apoyo de políticos neoconservadores, quienes son considerados detractores del gobierno de Ahmadi Neyad; una evidencia de que la coyuntura internacional ha sido una variante de la que han dependido los moȳähedìn, mucho más que de sus propias estrategias internas.

Estas consideraciones hacen concluir también que la organización está encaminada a ganar el favor de sus aliados y no el de la ciudadanía iraní, una ciudadanía que ha otorgado su con- 
fianza a proyectos de reforma internos, tales como el Movimiento Verde, más que a plataformas que incluyan un hipotético ataque militar a la nación iraní, intervención que en la coyuntura, al momento de escribir estas notas, es sumamente lejano e improbable. Por lo tanto, el interés de los moȳāhedin es básicamente sobrevivir como organización, pues no tienen ninguna posibilidad de empoderarse socialmente y mucho menos de gobernar Irán dada su historia mercenaria y sus fallas en la articulación de intereses con la ciudadanía iraní.

Finalmente, el acercamiento reciente con Occidente tampoco puede suponer que los moȳähedin sean aliados indiscutibles de la élite neoconservadora de Washington, ya que, como se observó a lo largo del artículo, han sido sólo una herramienta temporal para las élites conservadoras de Estados Unidos, que en momentos idóneos los han usado para disentir o consensuar con Irán temas relacionados con su proyecto nuclear y las sanciones económicas. Por tal motivo, aunque los moȳähedìn siguen vivos como organización política mercenaria de algunos grupos contrarios a Teherán, y aunque son el grupo de oposición mejor organizado fuera de Irán, su proyecto de gobernar bajo una "República Islámica Democrática" ha quedado rebasado, no sólo por sus errores tácticos en la historia, sino también por las condiciones geopolíticas que los han orillado a lo que son ahora, es decir, un pequeño vestíbulo en el exterior y un culto en el interior, sin ningún peso regional significativo y con un objetivo muy claro: estrictamente, la supervivencia política.

Dirección institucional del autor:

Facultad de Ciencias Políticas y Sociales

Universidad Nacional Autónoma de México

Circuito Mario de la Cueva s/n

Ciudad Universitaria,

Coyoacán

04510, México D. F.

mgarduno@politicas.unam.mx 


\section{Bibliografía}

Abrahamian, E., Radical Islam: The Iranian Mojahedin, Londres, Tauris, 1989.

Abrishamchi, M., Falsafah-'i imām zamān, Teherán, Anjuman-i dānishjūyān-i musalmān-i Dānishkadah-i Pulī Tiknīk, 1980.

Abbare Iran, "17 Shahrivar Salgarde Koshtare Mardom Tawassote Regime Shah", video subido por Hambastegui Meli el 7 de septiembre de 2011. [www.youtube.com/watch?v=2KlLuKZ56 Lg\&feature $=$ related, consultado el 1 de septiembre de 2015.]

AhmadinejAD, M., "Yahan bediun sihiunism", video subido por Shahid Witness el 26 de septiembre de 2012. [www.youtube. com/watch?v $=$ LffqGiiX6kA, consultado el 21 de agosto de 2015.]

Al Jazeera Desk, "Iranians Mourn Dissident Cleric", Al Jazeera, 21 de diciembre de 2009. [www.aljazeera.com/news/middleeast/2009 /12/2009122143345186480.html, consultado el 15 de abril de 2014.]

Alhomayed, Tariq, "He'd be Lucky to share Mubarak's Fate", Ashar Al Awsat, 11 de julio de 2012. [www.aawsat.net/2012/07/article55241405/hed-be-lucky-to-share-mubaraks-fate, consultado el 3 de agosto de 2015.]

Arjomand, S., After Khomeini: Iran under his Successors, Oxford, Oxford University Press, 2009.

BAKHASH, S., The Reign of Ayatollabs: Iran and the Islamic Revolution, Nueva York, Basic Books, 1984.

Bush, G. W., "State of the Union Address", Washington, Office of the Press Secretary, 29 de enero de 2002. [georgewbush-whitehouse. archives.gov/news/releases/2002/01/print/20020129-11.html, consultado el 12 de abril de 2014.]

Clifford, B., The Marketing of Rebellion: Insurgents, Media, and International Activism, Cambridge, Cambridge University Press, 2005.

COHEN, R., The Rise and Fall of the Mojahedin Khalq, 1987-1997: Their Survival after the Islamic Revolution and Resistance to the Islamic Republic of Iran, Brighton, Sussex Academic Press, 2009.

Consejo de Seguridad de las Naciones Unidas, "Resolución 598 del 20 de julio de 1987". [www.un.org/es/comun/docs/?symbol=S/ RES/598\%20(1987), consultado el 2 de septiembre de 2015.]

Dabashi, H., Theology of Discontent: The Ideological Foundations of the Islamic Revolution in Iran, Nueva York, New York University Press, 1993. 
Foreign Affairs Committee of the National Council of Resistance of Iran, Democracy Betrayed: A Response to U.S. State Department Report on the Mojahedin and the Iranian Resistance, Auvers-sur-Oise, Foreign Affairs Committee of The National Council of Resistance of Iran, 1995.

GARDUÑo, M., "La articulación de objetivos y el marketing político como estrategias de supervivencia en el cambio organizacional de los Moȳāhedīn-e Jalq-e Iran, 1964-2012”, tesis doctoral, Madrid, Universidad Autónoma de Madrid, 2012.

GARDUÑO, M., "Le modèle des pāsdārān-artesh: préoccupations internes et défis externes dans le cadre du printemps arabe", $M a-$ ghreb-Machrek, núm. 214, invierno de 2012, pp. 71-84.

Hạ Shenās, 'Intishār ârshîf sāzmfn peȳkār dar rāh âzādì tabaqeh-ȳe kārôar torāb haq shenās, París, Sāzmān Peȳkār, 2011.

Hersh, S., “Our Men in Iran?", The New Yorker, 6 de abril de 2012. Hizb-I Tūdah-'i İrān, Shah's Secret Police, París, Central Committee of Tudeh-Party of Iran, 1976.

Human Rights Watch, Endless Torment: The 1991 Uprising In Iraq and its Aftermath, Nueva York, Human Rights Watch, 1992. [www.hrw.org/reports/1992/Iraq926.htm, consultado el 21 de octubre de 2014.]

Islamic Media Front, "Assassination Attempt on Ayatollah Khamenei by Munafiqeen-e-Khalq Western Backed Terrorist Organization”, video subido por Islamic Media Front el 27 de agosto de 2008. [www.youtube.com/watch? $=$ BBUWCbu4kxs, consultado el 2 de septiembre de 2015.]

Jafarzadeh, A., The Iran Threat: President Abmadinejad and the Coming Nuclear Crisis, Nueva York, Palgrave, 2007.

KALEMEH, "Moȳāhedīn-e Jalq: nemād va ebstegījashvanat va turūd dar Irān”, Kalemeh (1390), 14 de agosto de 2011. [www.kaleme. com/1390/05/23/klm-69203/, consultado el 1 de abril de 2014.]

Katzman, K., The People's Mojahedin Organization of Iran, Washington, Congressional Research Service-Library of Congress, 1992. [www.iran-interlink.org/files/child\%20pages/USstatedept. htm\#CURRENT ACTIVITIES, consultado el 3 de abril de 2014.]

Khadivar, M. y A. Sadri, "Hillary Clinton's Crucial Choice on Iran", Salon, 26 de marzo de 2011. [www.salon.com/2011/03/26/ iran_green_movement/, consultado el 15 de abril de 2014.]

Kifner, J., "Iranian Bomb Deaths could Spark Power Struggle", The Times Neres, 1 de julio de 1981. [www.news.google.com/newsp apers? $\mathrm{id}=\mathrm{ED} 8 \mathrm{aAAAAIBAJ} \&$ sjid $=$ RiQEAAAAIBAJ\&pg $=677$ 
6,95902\&dq = beheshti $+1981 \& \mathrm{hl}=$ en, consultado el 15 de agosto de 2014.]

MESA, L., El debate sobre la seguridad nacional en la República Islámica de Irán: estudio del primer mandato del presidente hojatoleslam Seyed Mohammed Khatami (1997-2001), México, El Colegio de México, 2009.

Ministerio del Interior de Irán, "Resultados oficiales de la elección presidencial iraní 2009”, Teherán, 2009. [moi.ir/Portal/Home/ ShowPage. aspx? Object $=$ News\&CategoryID $=832 \mathrm{a} 711 \mathrm{~b}-95 \mathrm{fe}-$ 4505-8aa3-38f5e17309c9\&LayoutID = dd8faff4-f71b-4c65-9aefa1b6d0160be3\&ID = 5e30ab89-e376-434b-813f-8c22255158e1, consultado el 21 de agosto de 2015.]

Mojahedin-e Khalq-e Organization, "Mojahedin Structure", Foreign Affairs Committee of the National Council of Resistance of Iran Bolletin, s.n., 23 de marzo de 2009. [www.iran-e-azad.org/english/special/chap9.html, consultado el 27 de febrero de 2014.]

Mu'assasah-'Imutāla'āt va Pizhūhish'hā-Yi Siyāsī (Irán), Sāzmān-i mujābidìn-i khalq: Paydāyàtāfarjām, 1344-1384. yalddovom (2), Teherán, Mu'assasah-i Mutāla'āt va Pizhūhishhā-yi Siyāsī, 2006. People's Mojahedin Organization of Iran, "june 2009 peyam e Maryam Rajavi baraye nedaye azadi e mardome iran", video subido por Khorshid Asadi el 24 de junio de 2009. [www.youtube.com/watch? $\mathrm{v}=0 \mathrm{BPyeq6JTN8}$, consultado el 3 de agosto de 2015.]

Press TV, "Musavi backed by Terror Group: Scholar", Press Tv Nerws, 7 de marzo de 2011. [edition.presstv.ir/detail/168658.html, consultado el 22 de octubre de 2014.]

Public Affairs Alliance of Iranian Americans (PAAIA), 2013 National Public Opinion Survey of Iranian Americans, Washington, comisionada por PAAIA y llevada a cabo por la George Mason University, 2013. [www.paaia.org/CMS/Data/Sites/1/ pdfs/survey-of-iranian-americans-2013.pdf, consultado el 4 de agosto de 2015.]

RezaeI, A. A., "Foreign Policy Theories: Implications for Foreign Policy Analysis of Iran", en Anoushiravan Ehteshami y Mahjoob Zweiri (eds.), Iran's Foreign Policy: From Khatami to Abmadinejad, Berkshire, Ithaca Press, 2008.

Ruiz Figueroa, Manuel, La religión islámica: una introducción, México, El Colegio de México, 2002.

SARABI, F., "The Post-Khomeini Era in Iran: The Elections of the Fourth Islamic Majlis", Middle East Journal, vol. 48, núm. 1, invierno de 1994, pp. 89-107.[www.jstor.org/discover/10.2307/4328 
663? uid $=3738664 \&$ uid $=2 \&$ uid $=4 \&$ sid $=21104869928947$, consultado el 21 de octubre de 2014.]

Sazman Muyahidin-e Khalq-e Iran, "Didarba Abu Amar”, Mojahed, núm. 6A (1359), 1979.

Sazman Muyahidin-e Khalq-e Iran, "Mayiraha-ye pishtparde-ye grugaangiri”, Mojahed, núm. 102 (2 Dey 1359), 23 de diciembre de 1980.

Sazman Muyahidin-E Khalq-E Iran, "Oiandeh enqelab", Mojahed, núm. 4 A (11 Bahman 1358), 31 de enero de 1980.

Sāzmān-i Mujāhidīn-i Khalq Iran, Prāgmātism, Teherán, Intishārāt-i Sāzmān, 1979.

Sāzmān-i Mujāhidīn-i Khalq Iran, Rāh-i anbiyā, rāh-i basher, Teherán, Sāzmān-i Mujāhidīn, 1979.

Sāzmān-i Mujāhidīn-i Khalq Iran, Sharḅta'sisswa-tārīkbih dāth munazzamat mujāhidì al-Sh'ab al-irānì min 'àmm 1965 wa-hatt'a' āmm 1971, Berkeley, al- Munazzamah, 1985.

Sāzmān-i Mujāhidīn-i Khalq İran, Shinākht [yā] mituduluzhì, Teherán, Sāzmān-i Mujāhidīn, 1972. [wwww.peykarandeesh.org/PeykarArchive/Mojahedin/Shenakht.pdf, consultado el 27 de febrero de 2014.]

SHAHSAWANDI, S., "Risheya bivatahulatba'd sazman mojahedin-e khalq (3) goftegu lotfollah meysami ba said shahsawandi”, manuscrito, 2012. [www.shahsawandi.com/index.php?option $=$ com content\&task $=$ view $\& i d=102, \&$ Itemid $=28$, consultado el $2 \overline{8}$ de febrero de 2014.]

SilversteIn, R., "Israeli Source: Assassination of Iranian Nuclear Scientist Joint Mossad-MeK Operation", página web de Richard Silverstein, 10 de enero de 2012. [www.richardsilverstein.com/2012/01/10/iran-blames-israel-for-assassinatinganother-iranian-nuclear-scientist, consultado el 10 de julio de 2012.]

SinaIEe, M., "Iran Hardliners pledge to oust 'Leaders of Sedition"”, The National, 9 de enero de 2011. [www.thenational.ae/news/ world/middle-east/iran-hardliners-pledge-to-oust-leaders-ofsedition, consultado el 15 de abril de 2014.]

Singleton, A., Saddam's Private Army: How Rajavi changed Iran's Mojabedin from Armed Revolutionaries to an Armed Cult, Londres, Interlink, 2003.

St. Petersburg Times Desk, "Bomb Blast kills Iran's President, Prime Minister", St. Petersburg Times, 31 de agosto de 1981.

Tasnim Newes Agency, "Iran, G5+1 to resume Expert-Level Talks in Vienna", Tasnimneres.com, 21 de octubre de 2014. [www. 
tasnimnews.com/English/Home/Single/535854, consultado el 21 de octubre de 2014.]

VAKILY, A., "In Search of Revolutionary Islam: The Case of Taleqani and Mojahedin", The Muslim World, vol. 88, núm. 1, enero de 1998, pp. 22-46.

Wallace, C. P., "Regained 2 Towns in Heavy Fighting, Iranians Report", Los Angeles Times, 30 de julio de 1988. [pqasb.pqarchiver. com/latimes/access/59826063.html?dids $=59826063: 59826063 \&$ $\mathrm{FMT}=\mathrm{ABS} \& \mathrm{FMTS}=\mathrm{ABS}: \mathrm{FT} \&$ type $=$ current $\&$ date $=\mathrm{Jul}+30 \%$ $2 \mathrm{C}+$ 1988\&author $=$ CHARLES + P. + WALLACE\&pub $=$ Los + Angeles + Times $+($ pre-1997 + Fulltext $) \&$ desc $=$ Regained $+2+$ To wns + in + Heavy + Fighting $\% 2 C+$ Iranians + Report\&pqatl $=$ goo gle, consultado el 14 de septiembre de 2014.]

ZABIH, S., The Left in Contemporary Iran: Ideology, Organization, and The Soviet Connection, Londres, Hoover Institution Press, 1986. ZACCARA, L., "Irán y EE UU: ni sanciones ni intervención”, Estudios de Política Exterior, núm. 139, enero-febrero de 2011. 
